\title{
Impact of digital technologies on the integration of labor migrants
}

\author{
Irina Fedorova ${ }^{1, *}$ and Valery Potemkin ${ }^{1}$ \\ ${ }^{1}$ St. Petersburg State University of Economics, St. Petersburg, Russian Federation
}

\begin{abstract}
Over the past decade, migrants have become increasingly interconnected, and this is actively facilitated by the development of the global Internet and the availability of modern channels of communication, such as telephones with access to the network. The impact of digital technologies on the integration of migrants is still not well studied in Russia. The aim of the study is to analyse the impact of digital technologies on the integration of labor migrants into St. Petersburg host society. For the analysis, we used sociological methods: a series of semistructured interviews with 23 labor migrants living in St. Petersburg, to identify the attitude of the host society (residents of St. Petersburg) to migrants we analyze of secondary survey data. The analysis of host community of St. Petersburg shows the contrariety in opinions. Only $37 \%$ citizens want migrants to integrate into society. During interviews, we found out that migrants are ready to accept digital ways for integration, such as special channels (groups) in social networks and applications for smartphones. $80 \%$ mentioned that they don't know about any programs for integration or opportunities from local organizations. As for digital opportunities, we found out that migrants rarely use web sites. Migrants prefer using social media to specific digital tools, websites or applications. They prefer chatting in WhatsApp and use Vkontakte social network.
\end{abstract}

\section{Introduction}

Modern migration processes are, perhaps, one of the main factors of social changes in different societies. According to E. Giddens, the transformation of spatial social relations is carried out under the influence of these processes [1].

Modern conditions create a situation where in the current demographic and socioeconomic situation it becomes impossible for a society to exist effectively. The migration flow is a part of the driving force of the society development. Over the past decade, migrants have become increasingly interconnected, and this is actively facilitated by the development of the global Internet and the availability of modern channels of communication, such as a telephone with access to the network [2].

\footnotetext{
* Corresponding author: iriska-hime@yandex.ru
} 
The use of digital technology allows migrants to keep in touch with their family and friends in the country of origin, while at the same time helping them to adapt and integrate in the host country. Sociologist Dana Diminescu, studying the relationship between the development of digital technologies and migration, explains how new technologies have changed migration processes and affected the lives of migrants [3]. The researcher concludes that the connection became clearly visible during the migration crisis of 2015 . Social technologies have an impact on transnational experience; migrants find sustainable ways to confront the difficulties associated with being in migration. Media has started using the word "technophoria" - literally associated with improving the conditions of migrants. For migrants, the development of the Internet and telephones with video cameras have become a valuable resource both for adaptation and integration in the host society and for maintaining connections with their origin country.

The problem is partly reflected in Yuna Kim's article "Digital media and intergenerational migration: Nannies from the global south" [4], published in the journal "Learning, Media and Technology", which examines the opportunities and limitations of digital media usage for national minorities, especially given the increasing prevalence among migrants (the author examines young women from the South). As the author rightly points out, transnational relations and practices are not necessarily a positive process, but they can also create new risks, or they may contribute to the normalization of risk.

The work of Gabriela Sanchez and a number of co-authors "A study of the communication channels used by migrants and asylum seekers in Italy, with a particular focus on online and social media" [5] published in 2018, also addresses this issue. The authors study migrants from Libya based on surveys, interviews and focus groups conducted in Italy with 686 migrants (including illegal migrants and refugees). The authors describe the impact of social media and mobile applications (including the use of smartphones), along with traditional channels of information (e.g. face-to-face, diaspora, radio, television and/or newspapers) about migration. The authors conclude that for making important decisions migrants prefer traditional channels of communication face-to-face or in a group (diaspora) instead of messaging or video calling applications (one of the main reason is the poor infrastructure in many countries of origin of migrants).

The role of social media as a communication channel is growing dynamically, while the use of applications and online platforms is diverse among migrants: their use has been quite limited among some migrants, and virtually absent among those who are citizens of countries where the Internet infrastructure is not developed.

These articles deal with international migration in general. We would like to note that the impact of modern, digital technologies on the integration of migrants is still not well studied in Russia. The aim of the study is to analyze the impact of modern digital technologies on the integration of labor migrants into St. Petersburg host society.

\section{Methods}

Saint Petersburg is the center of attraction for internal and external migrants. The relevance of the study has a number of factors. Firstly, the increase of number of migrants has both positive and negative sides. The positive aspects include the maintenance of an optimal balance of labor resources and the sort of solution of Russian demographic problems. As for negative aspects, we can mention the growth in the number of illegal migrants, failure to respect the rights of legal migrants. Secondly, with the increasing number of migrants there is an increase of xenophobic attitudes of the host population (which we will describe later), therefore it becomes important to find out aspects of migrants ' adaptation to the new 
environment and their integration and simultaneously work with the host society in relation to the formation of tolerance toward migrants.

Moving to a different culture, different living conditions are a stressful factor. To overcome this stressful situation migrants need social support, which may be given via digital resources. Positive adaptation of migrants is in the interest of the migrants themselves and the host society.

Methodological basis for the study was selected on the basis of the analysis of the literature on the problem, research methodology, and based on the study of the work of The Committee on interethnic relations and implementation of migration policy in SaintPetersburg, consulting the sector of social structure study of department of sociology, innovation and social structure in the Sociological Institute of the Russian Academy of Sciences.

\subsection{Theoretical and methodological basis of the article.}

The study of the behavior of migrants in a new place in the context of its interaction with the host society has become important in recent decades in migration studies. In the early work on post-immigration processes Thomas and Znanecki in their monograph the "Polish peasant in Europe and America" [6] concluded that Polish migrants do not remain "Polish" and do not become "American", but rather form a new ethnic group of so called "Polish Americans". Based on this, more advanced theories of migrant assimilation processes were further developed. Milton M. Gordon proposed a multi-step model that identifies the phases that migrants go through during a typical assimilation process, leading to full identification with a host society. In his book "Assimilation in American life", written in the early 1960s, Gordon distinguishes seven stages of assimilation [7]: acculturation (the adoption to norms and values), structural assimilation (inclusion in the institutions of the host society), marital assimilation (the emergence and spread of intermarriage), identification assimilation (the relationship of minority with the majority), behavioral assimilation (absence of discrimination against minorities), value assimilation (linked to lack of prejudice) and civic assimilation (linked to the lack of conflict between internal representations of the individual and values of the host society). It is important to note here that in those years assimilation was seen as the only way, natural and inevitable, to include representatives of other cultures in society.

Gordon paid great attention to the first two stages - acculturation and structural assimilation. According to Gordon, acculturation can occur without other types of assimilation, and it can last indefinitely. R. Alba and V. Ni presented their "new theory of assimilation", in which they emphasize that assimilation also entails adaptation from the part of the host society and its institutions [8]. The revised theory of assimilation as understood by R. Alba and V. Ni suggests the reduction of cultural and ethnic boundaries between migrants and the host community. The authors do not deny the existence of a dominant culture. While some modern theories of assimilation are complex, many migration researchers beware their validity and normative basis.

These trajectories in the migration study and related processes have had a strong impact on the science development. The analysis of the assimilation process assumes that migrants are a group with their own traits and characteristics. Recently, however, this thesis has been subjected to reasonable criticism. Modern sociologists, based on a large base of collected data, argue that empirical studies have recorded neither migrants nor group solidarity, nor the integrity of the subject of behavior, and there is a lack of effective communication within a limited team [9]. 
The criticism of "groupism" in the analysis of assimilation process is raised in the studies of R. Brubaker, who argues that "the group seems to be a problem-free, selfevident concept that does not require special analysis or explanation. As a result we begin to consider for granted not only the concept, but "group" — imaginary things-in-the-world refers to this concept" [10]. From the sociological point of view, it is necessary to critically rethink the concept of a group in the context of migrants' study, since a migrant is a person who can be classified as a "migrant" for a number of characteristic features.

In the late 1990s, a new concept of explaining migration and integration was spread in Europe - transnationalism. This concept, based on the objective prerequisites of widespread development of the Internet, intensification of air traffic, development of communication technologies between people, says that ethnic groups and Diasporas, which were discussed earlier, no longer exist [11]. There are transnational networks and communities [12]. Migrants in this theory are dependent on contacts both in the country of origin and in the new environment. For example, migrants living in another country can invest in business development at home. Transnational migrants have an impact on both the host country and the country of origin [13]. The concept of transnationalism is reflected in the works Of N. G. Schiller, [14], P. Levitt [15], N. Glazer and D. Moynihan [16] and others.

Due to the development of technology and the wide availability of transport and communication, migrants are able to maintain more contact that is frequent with their home societies than before. In addition to technological progress, another important factor contributing to transnationalism is the demographic situation of developed countries. Migration fills the demographic gaps caused by population decrease in developed countries. Today migration accounts for $3 / 5$ of the population growth in Western countries as a whole, and this trend continues. Under the concept of transnationalism, when migrants engage in transnational activities, they form the social fields that link the country of origin to the new country. These social fields are the result of a series of interrelated economic, political and socio-cultural actions. The concept of transnationalism is the idea of including people in more than one community. Migrants become members of a special, transnational social space, while independently choosing the vector of inclusion in public life [17].

Digital technologies play an important role in migrants' life. Mobile phones and internet erase barriers between the country of origin and social connections there and the current society. Communication technology has made a big step forward during last 10 years. Migrants spread information very fast, but does it help in the process of their integration? Or it causes their closeness towards the host society? To examine this phenomenon, we conducted empirical research.

\subsection{Empirical research}

We conducted a series of semi-structured interviews with 23 labor migrants living in St. Petersburg. For the interview, we used the snowball method. Interviews were conducted in 2018 and 2019 with labor migrants from Tajikistan, Uzbekistan, Kyrgyzstan, Azerbaijan and Armenia. In the interview, we focused on the topic of integration into the host community, the causes and purposes of migration, ways to interact with each other and with relatives left in the countries of origin.

Among the respondents 30\% were Uzbeks, 30\% - Kyrgyz, 20\% - Tajiks, 10\% were Azerbaijanis and Armenians. Among them 40\% - women, $60 \%$ - men. $85 \%$ of respondents are of working age, $15 \%$ - older than working age. One third of respondents have higher education, $65 \%$ - secondary special and secondary general education (school). 
Most of them are married (70\%), single $-22 \%$, widowed $-9 \% .80 \%$ of them have children. Legal status: $15 \%$ of respondents received citizenship of the Russian Federation, the absolute majority $(85 \%)$ has only temporary registration in Russia. Areas of employment: $20 \%$ of respondents (with secondary education) are engaged in work that does not require qualification, $50 \%$ of interviewees are skilled workers (among them $20 \%$ of migrants have higher educations). $30 \%$ of our samples of migrants work in services. Moving to St. Petersburg lowered the social status of all respondents without exception, according to both subjective and objective assessments. Russian language was called native by $25 \%$ of respondents, explaining that they were born and lived in one country - the USSR, where "nationality was on the second place." According to the dates of arrival, the distribution was as follows: $10 \%$ of migrants arrived in the period from 1990 to $2000,50 \%$ came to St. Petersburg in the period from 2001 to 2015 and $40 \%$ came after 2015.

\section{Socio-psychological characteristics}

According to the study's hypotheses, self-assessment of migrants is an important indicator of successful adaptation and integration. In general, interviews showed that self-assessment of migrants is in the normal range, but is prone to understatement, those who have recently arrived in Saint Petersburg. Adaptive strategies dominate the non-adaptive, migrants tend to integrate into the host society, but face a number of difficulties, which include legal (obtaining citizenship), economic (salary estimated migrants as "low"), social (in particular, main reason is a lack of time to integrate into society due to over-employment).

\section{Characteristics of migration}

Categories of analysis: motives of migration, types of migration objectives. The motives of migration were mostly economic (75\% of migrants), than educational $(15 \%)$, and family reunion (10\%). Those who came for family reunion reasons, who also received citizenship of the Russian Federation, mentioned irrevocable migration. The majority of respondents (both labor and education, 90\%) are in a temporary migration. The goals of migration are also transparent: economic, educational, family. Analysis of the interviews showed that, indeed, migrants who got citizenship, show a higher percentage of adaptability, better use the Russian language, celebrate Russian national holidays (except Orthodox) and raise children, adhering to integration goals. As for labor migrants, they show less interest in integration into Russian society, they rather have their own practices and spend time with people of the same nationalities as they are (family members, friends). Women from Tajikistan A., 26 years old, cleaner: "We spend weekends with my husband. Buy food, cook. Sometimes we go to shopping centers. I like to walk in parks". In the answers a lot of interviewees mentioned "migrants cafes" - authentic places with traditional cuisine (there are a lot of them in St. Petersburg, mostly visited by migrants where they communicate on their language, listen to their music and dance). They mentioned social connections via smartphones (SMS, WhatsApp, sometimes- VK network) for receiving information about useful things for them - mostly for helping with solving problems with work, places to live, legal issues, healthcare or helping families in case of accidents. Much less they share information about leisure topics (cafes, special events) and others. N., 39-years old worker from Uzbekistan: "We have special websites where we share information about accommodation in Petersburg. It helps for those who have just come to the city". 


\section{Migration strategies}

The socio-economic behavior of migrants determines their adaptation strategies. We traced the connection: migrants adapt to the conditions of the host society with varying success due to different purposes of their arrival. Migrant adaptation strategies do indeed depend on the purpose and motive of migration - migrants who come for educational, family and political reasons and want to stay in the city are willing to integrate. Labor migrants are suspicious to integration, those whose main motive is to improve the financial situation of the family (in $30 \%$ of the responses they do not express interest in living according to the rules of the local society, although they try not to limit children exclusively to their traditional way of life, they try to instill a "symbiosis" of norms and values). While the children of migrants live without them in the country of origin with their grandparents and other relatives. In this situation all labor migrants said that cell phones really help them to overcome this territory gap and see their children via WhatsApp video chat every day. Women from Kyrgyzstan K., 33 years old, cleaner: "My husband decided to move to St. Petersburg together, we need to buy a house for our family. My two kids live with my husband `s parents and his brothers. We communicate in WhatsApp every day. We send money to them. It's hard for me. We need 3 more years to earn money. I miss kids so much (starts crying)".

Interestingly, $100 \%$ of the interviewees rent a house and do not have a residence permit. At the same time, all migrants are characterized by poor knowledge or ignorance of the opportunities that are provided to them by the state, social services, national diasporas. Social and psychological adaptation in such cases is unsystematic, migrants are left to themselves. The attitude of the local society to migrants they mostly defined as "good" (those respondents who live in St. Petersburg for more than 3 years), and as "normal" (so evaluated the attitude of migrants who came after 2015).

\section{Digital opportunities for migrants}

During interviews, we found out that migrants are ready to accept digital ways for integration, such as special channels (groups) in social networks and applications for smartphones. $80 \%$ mentioned that they don't know about any programs for integration or opportunities from local organizations, but they said that they are fully aware of their national diasporas and national activities in St. Petersburg. This creates a big threaten of radicalization and the growing alienation of migrants from the life of the local community. Although there are several websites for migrants in St. Petersburg: http://migrantinfo.kmormp.gov.spb.ru/ (available only in Russian)- provided by local government, it is the resource for migrants that contain basic useful information about St. Petersburg, a brief historical background, the basics of migration legislation, information about cultural events and cultural institutions, rules of conduct in public places, the traditions of St. Petersburg, the procedure for action in extreme cases and many other useful information. http://tutjdut.ru/ - resource for migrants with slogan "Easy Russia for migrants", it is available in different languages and has information about legislation, job opportunities, accommodation, news from "migrants world", diasporas and CIS countries.

There are 13 groups for helping migrants in the most popular social network in Russia "vkontakte" (vk.com). Most of them provide services for migrants (mostly paid services), such as legal support, support in native language when applying for a patent for employment, job offers, support with living conditions, and support with children adaptation. The analysis of number of participants shows that these groups are popular among migrants (i.e., in the group "Protection of Migrants in SPB / Registration / Residence permit / Patent" there are 3159 active members [18]). 


\section{Analysis of the host community}

The attitude of host society influences the migrants' integration processes. To identify the attitude of the host society (residents of St. Petersburg) to migrants we analyze of secondary survey data. The categories of the analysis are social distance, tolerance and attitude to integration of migrants.

Levada Analytical Center [19] monitors xenophobic attitudes among the residents of Russia. The representative study of the Russian population aged 18 years and older $(\mathrm{N}=1608$ people) was conducted by personal interview on August 22-28, 2019. According to its results, a list of possible answers related to ethnic and migrant issues have been selected more often than a year ago on the problems that most concern Russian residents (see Picture 1).

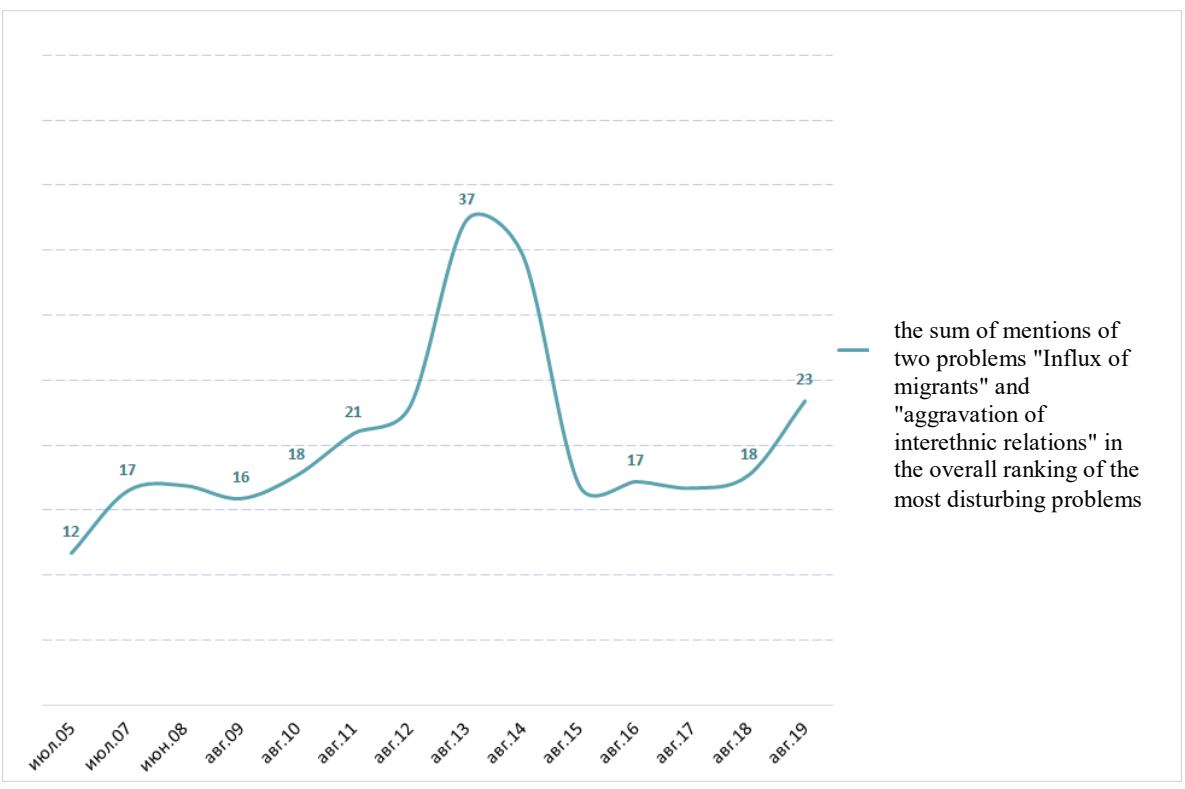

Fig.1. The sum of mentions of two problems "Influx of migrants" and "aggravation of interethnic relations" in the overall ranking of the most disturbing problems.

The growing attention to the migrant theme is confirmed by the results of another question aimed at identify the focus of ethnic hostility of the local population. Data from 2017 to 2019 indicate a steady increase in the intensity of responses, where respondents name more often certain ethnic groups whose residence they would like to limit on the territory of the Russian Federation. The overall level of ethnophobia - a measure of the proportion of those who generally name one or more categories, according to Levada - has also increased over the period, from $54 \%$ to $71 \%$, and is close to the level of $2012-2013$ (see Picture 2). 


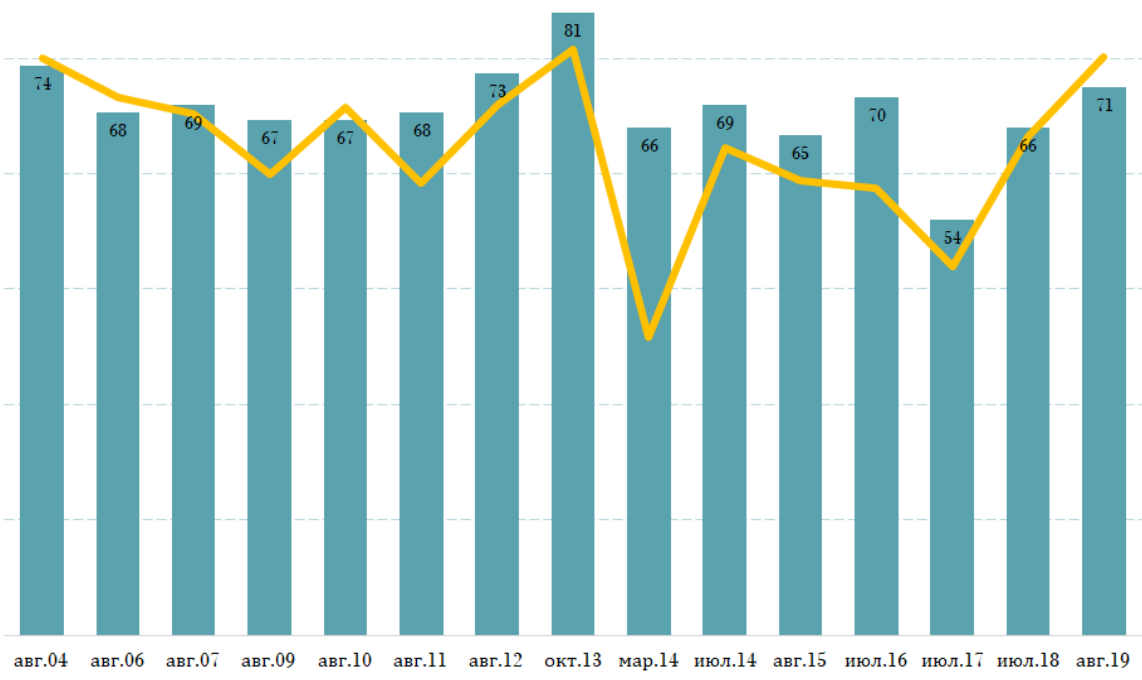

Fig. 2. The overall level of ethnophobia.

For describing the situation in Saint Petersburg we used sociological data analys of the survey conducted in 2016 by St.Petersburg State University Resource Center "Center for Sociological and Internet Research" ( $\mathrm{N}=1017)$ [20]. According to the distribution of answers to the question "In your opinion, is the situation with migrants in St. Petersburg today better, worse or at an average level compared to other Russian regions?" citizens tend to consider the situation in St.Petersburg the same in comparison to other Russian regions. Every 10th citizen consider the situation in St.Petersburg worse than in other regions.

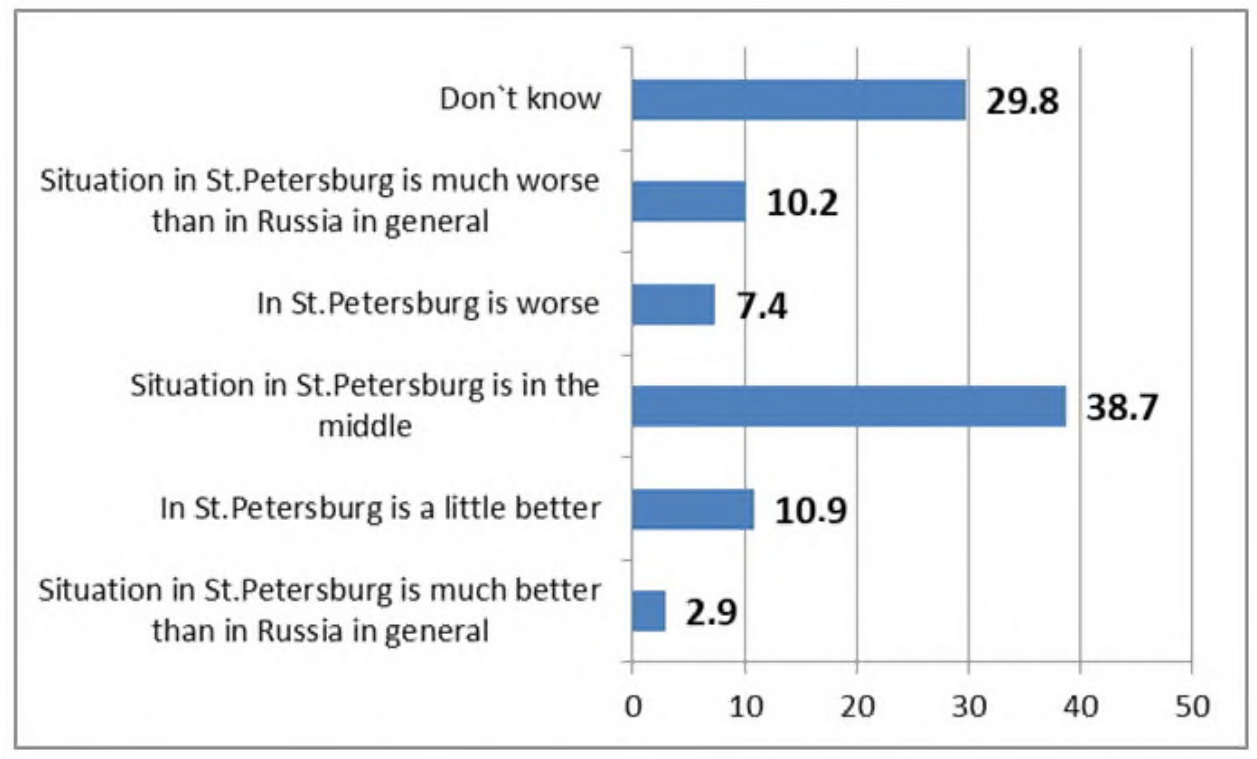

Fig. 3. Distribution of answers to the question "In your opinion, is the situation with migrants in St. Petersburg today better, worse or at an average level compared to other Russian regions?" 
Another answers show contrariety in opinions of St.Petersburg citizens. On the one hand, $70 \%$ of citizens understand the necessity of migration, on the other hand - only $7.5 \%$ citizens expressed willingness to increase the number of migrants. More thn half citizens want to decrease the migration flow to St.Petersburg (see picture 4).

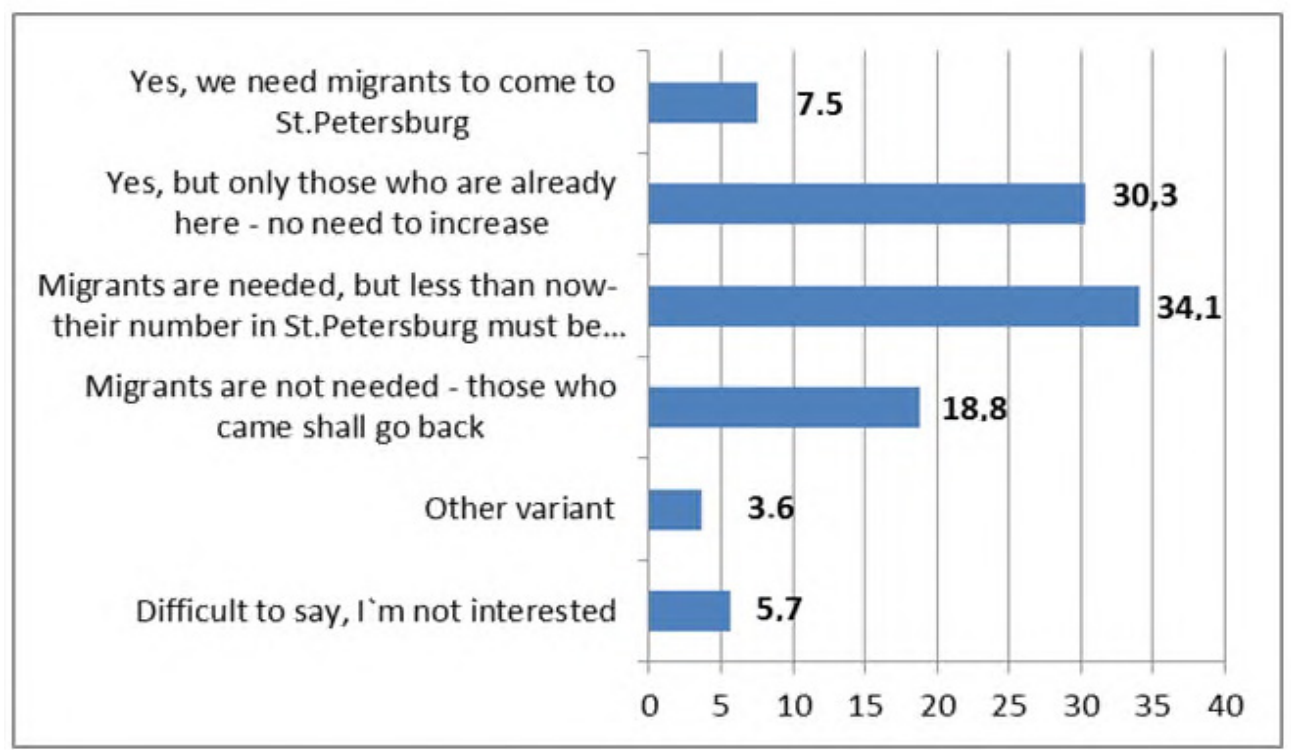

Fig. 4. Distribution of answers to the question "What is your opininon, do we need migrants in St.Petersbu 'rg today?"

The analysis of attitude of host society towards migrants and migration shows the contrariety. Xenophobic stereotypes are present in the mass consciousness along with positive assessments of the practical experience of interaction with migrants. $38 \%$ are supporters of integration of migrants. Host society demonstrates fatigue from gastarbeiters and wants replacement on "ideal migrants" - young, educated, focused on acculturation and integration into the Russian society.

\section{Results and Discussions}

Analysis of the conducted interviews showed that those migrants who got citizenship, showed a higher percentage of adaptability, better usage of the Russian language, willingness to celebrate Russian national holidays (except Orthodox) and to raise children, adhering to integration goals. As for labor migrants, that are the most common migrants in St. Petersburg, they showed less interest in integration into Russian society. They would rather have their own practices and spend time with people of the same nationalities as they are.

In their answers, many interviewees mentioned social connections via smartphones (SMS, WhatsApp, sometimes- VK network) for receiving information about useful things for them - mostly for helping with problems with work, finding places to live, legal issues, healthcare or helping families in case of accidents. They prefer spending leisure time in "migrants' cafes" - authentic places with traditional cuisine (there are a lot of them in St. Petersburg, mostly visited by migrants where they communicate on their language, listen to their music and dance). Although there are several websites for migrants in St. Petersburg, 
13 groups for helping migrants in "vkontakte" (vk.com), $80 \%$ of interviewees mentioned that they don't know about any programs for integration or opportunities from local organizations, but they said that they are fully aware of their national diasporas and national activities in St. Petersburg.

Xenophobic stereotypes are present in the mass consciousness along with positive assessments of the practical experience of interaction with migrants. The analysis of host community of St. Petersburg shows the contrariety in opinions. Only 37\% citizens wants migrants to integrate into society.

\section{Conclusions}

The development of the global Internet and the availability of modern channels of communication, such as a telephone with access to the network, facilitates migration. During interviews, we found out that migrants are ready to accept digital ways for integration, such as special channels (groups) in social networks and applications for smartphones. $80 \%$ mentioned that they don't know about any programs for integration or opportunities from local organizations, but they said that they are fully aware of their national diasporas and national activities in St. Petersburg.

As for digital opportunities, we found out that the sites are rarely used by migrants. Migrants prefer using social media over specific digital tools, websites or applications. They prefer chatting in WhatsApp and use Vkontakte social network. For purposes of integration, we need to pay attention to the digital opportunities and migrants preferences. The Internet is an ideal tool for the integration of migrants. Groups in social networks may be created on behalf of the official communities that represent a particular Diaspora in Russia and help labor migrants to adapt in Russia and integrate.

The reported study was funded by RFBR, project number 19-311-90027.

\section{References}

1. Giddens E. Sociology / with participation of K.Berdsoll. M., 2005.

2. How has digital technology changed migrants' lives? https://blogrecherche.wp.imt.fr/en/2018/12/20/digital-technology-migrants-lives/ Date: 15.09.2019

3. Diminescu D. Introduction: Digital methods for the exploration, analysis and mapping of e-diasporas. - Social Science Information 51(4), 201. 2012, p.451-458

4. Youna Kim . Digital media and intergenerational migration: Nannies from the global south. The Communication Review, 20:2. 2017, p.122-141.

5. Sanchez G., Hoxhaj R., Nardin S., Geddes A., Achilli L., Kalantaryan R.S. A study of the communication channels used by migrants and asylum seekers in Italy, with a particular focus on online and social media. Cadmus, EUI Research Repository, 2018.

6. Thomas W., Znaniecki F. The Polish peasant in Europe and America. New York, 1958. P.741.

7. Gordon, Milton Myron. Assimilation in American Life: The Role of Race, Religion, and National Origins. New York: Oxford University Press, 1964.

8. Alba R., Nee V. 2003. Remaking the American mainstream: Assimilation and contemporary immigration. Cambridge. Mass.: Harvard University Press. 359 p. 
9. Lisitsyn P. P., Ermakova M. A. "Groupism" in the study of migration: pros and cons of the categorical approach. - Actual problems of sociology and management: interuniversity collection of scientific papers.- Publisher: St. Petersburg state University, 2017. P.72-78.

10. Brubaker R. Ethnicity without groups. M.: Higher school of Economics, 2012, p.23.

11. Alvaro Lima. Transnationalism: A New Mode of Immigrant Integration // The Mauricio Gastón Institute, University of Massachusetts Boston, 100 Morrissey Boulevard, Boston, MA 02125 // http://www.bostonplans.org/getattachment/b5ea6e3ae94e-451b-af08-ca9fcc3a1b5b/ Date: 12.09.2019.

12. Portes, A. Immigration theory for a new century : Some problems and opportunities // International Migration Review 31 (4), 1997. - P. 812

13. Faist, T. Transnationalization in international migration : implications for the study of citizenship and culture // Ethnic and Racial Studies, 2000. - pp. 194-196

14. Glick Schiller N., Basch L., Szanton Blanc C. From Immigrant to Transmigrant: Theorizing Transnational Migration. Anthropological Quarterly, 1995, 68(1), pp. 4863.

15. Levitt, P. God Needs No Pass. Immigrants and the Changing American Religious Context. New York, London : The New Press, 2007.

16. Glazer N., Moynihan D. Beyond the Melting Pot, Second Edition: The Negroes, Puerto Ricans, Jews, Italians and Irish of New York City. Cambridge: MIT Press, 1970.

17. Amelina A. Transnationale Migration jenseits von Assimilation und Akkulturation: Transnationale Inklusion und hybride Wissensordnungen als konzeptionelle Alternativen zur Assimilations und Akkulturation debate // Berliner J. fur Soziologie. B., 2010. - Bd.20, H.2. - S. 257-279.

18. The group "Protection of Migrants in SPB / Registration / Residence permit / Patent" // URL: https://vk.com/migrant_russia Date: 30.09.2019.

19. Monitoring of xenophobic attitudes, year 2019. URL: https://www.levada.ru/2019/09/18/monitoring-ksenofobskih-nastroenij-2/ Date: 28.09.2019.

20. The International Migration in Saint Petersburg: Migration Policy and Public Opinion / edited by O.I. Borodkina, N.V. Soloviev, A.V. Tavrovskiy. - SPb.: Skifia-Print, 2017. - p.142-156. 